\title{
RAPEGA
}

O ESPACO GEOGRÁFICO EM ANÁL.ISE

\section{AS GEOTECNOLOGIAS COMO FERRAMENTA PARA O DIAGNÓSTICO DA ARBORIZAÇÃO URBANA: O CASO DE MACAPÁ, AMAPÁ.}

\section{THE GEOTECHNOLOGIES AS A TOOL FOR THE DIAGNOSIS OF URBAN FOREST: THE CASE OF MACAPÁ, AMAPÁ.}

\author{
Hugo Santos de Castro \\ Universidade Federal do Pará - UFPA \\ Guamá, PA, Brasil \\ e-mail: hcastrogeo@yahoo.com.br
}

Teresa Cristina Albuquerque de Castro Dias Instituto Brasileiro do Meio Ambiente e dos Recursos Naturais

Renováveis

Florianópolis, SC, Brasil

e-mail: teresa.cristina.dias@gmail.com

Viviane Vanessa Vilhena Amanajás

Secretaria de Estado do Meio Ambiente do Amapá

Macapá, AP, Brasil

e-mail:vivi amanajas@yahoo.com.br

\section{Recebido em: 27/07/2015}

Aceito em: 01/06/2016

\section{Resumo}

O objetivo deste trabalho foi realizar um levantamento inédito da arborização das vias públicas de Macapá através do método de amostragem, diagnosticando diversas variáveis silvimétricas que possam auxiliar o poder público a traçar um planejamento urbano, no trato da arboricultura. Foram utilizados o software BioEstat 4.0 para sortear $10 \%$ das quadras da cidade, bem como o software ArcGIS 8.3 para elaboração dos mapas temáticos produzidos após o levantamento. Registrou-se 2.092 indivíduos, distribuídos em 57 espécies, sendo $56 \%$ exóticas. No entanto, apenas três espécies: Mangifera indica L. (mangueira), Ficus benjamina L. (fícus) e Syzygium malaccense L. (jambeiro) concentram mais da metade $(57,4 \%)$ do total amostrado, o que foge às recomendações da literatura. $\mathrm{O}$ índice de árvores por 
habitante é de apenas 0,07. Outros dados como conflito com fiação eletrotelefônica, tutoramento do indivíduo para evitar problemas com sistema radicular e bifurcação, também merecem melhores cuidados por parte da gestão pública, assim como melhor distribuição nos três setores do município. A priorização de políticas públicas destinadas à arborização municipal e a utilização de ferramentas geotecnológicas em planejamentos futuros podem possibilitar a melhoria das condições urbanísticas e paisagísticas da cidade, compatibilizando, ainda, com a cultura local.

Palavras-chave: árvore; vias públicas; geoprocessamento; inventário.

\begin{abstract}
The aim of this work was to develop a new survey of arborization of Macapás public streets through a sampling method, diagnosing various silvimétricas variables that can support the government to draw a urban planning in dealing with arboriculture. BioEstat 4.0 software were used to raffle $10 \%$ of city blocks, and the ArcGIS 8.3 software for creation of thematic maps produced after the survey. 2.092 specimens were registered belonging to 57 species, of which are $56 \%$ exotic. However, only three species: Mangifera indica L. (mango), Ficus benjamina $L$. (ficus) and Syzygium malaccense $L$. (jambo) concentrate more than half $(57.4 \%)$ of all samples, which is not according to the literature recommendations. The index of trees per habitant is only 0,07 . Other data such as conflict with electrotelephonic wiring, the tree staking to avoid problems with root system and bifurcation also deserve better care by the public politician, as well as better distribution in the three municipal sectors. Prioritizing public policies aimed at municipal arborization and the use of geotechnologies tools in future planning may enable the improvement of urban and landscape conditions of the city, making compatible also with the local culture.
\end{abstract}

Keywords: trees; public streets; geoprocessing; inventory.

\title{
1. INTRODUÇÃO
}

Inúmeros benefícios são conferidos à arborização nas vias públicas. São benefícios ecológicos, estéticos e sociais, entre os quais: melhoria no conforto térmico, na avifauna local, poluição atmosférica, proteção do solo, lazer, valorização mobiliária (BIONDI, 2008). Bargos e Matias (2011) acrescentam ainda as funções psicológicas e educativas da arborização urbana. Tem-se, portanto, que em meio ao processo vertiginoso de urbanização das cidades brasileiras, árvores significam qualidade de vida no ambiente urbano. 
Para Sanchotene (1994), arborização urbana é o conjunto de terras públicas e privadas com vegetação predominantemente arbórea que uma cidade apresenta. Outros autores referem-se ainda, como um conjunto de vegetação arbórea natural ou cultivada que uma cidade apresenta em áreas particulares, praças, parques e vias públicas (BIONDI, 2008; BARGOS; MATIAS, 2011; SZEMERETA; ZANNIN, 2013).

Trabalhos como o de Milano (1991), corroboram a ideia de que a arborização urbana tecnicamente é dividida em: arborização de ruas e áreas verdes e esta última subdivide-se em: áreas verdes públicas e privadas. No entanto, Bargos e Matias (2011) atentam para a ausência de uma definição consensual dos termos, em que pese os diversos usos de sinônimos que a vegetação urbana recebe e as diferentes nomenclaturas que são utilizadas indistintamente como sinônimos do termo áreas verdes. Londe e Mendes (2014) deduzem que essa falta de consenso pode estar vinculada ao fato de a vegetação ser abordada sob diferentes perspectivas em ciências como Geografia, Biologia, Engenharia Florestal, Arquitetura, dentre outras, o que prejudica na avaliação da vegetação presente nas cidades e na comparação das pesquisas realizadas.

Cidades com ruas arborizadas abrem precedentes para implantação de áreas verdes como parques urbanos. A cidade de Macapá não há uma área legalmente instituída para esses fins, cujos benefícios vão além de recreativos. Szeremeta e Zannin (2013) elencam as funções ecológicas, estéticas e de lazer de parques e áreas verdes na promoção da qualidade de vida em cidades.

Segundo Lima Neto et al. (2010) a arborização de cidades é uma atividade que vem sendo praticada no Brasil há pouco mais de cem anos e na contemporaneidade a geotecnologia é uma ferramenta imprescindível para realizar levantamentos e posteriores proposições, com o uso não só de mapas, mas também de GPS (Global Position System) aliados a aerofotogrametria, imagens de satélite e softwares de SIG (Sistema de Informação Geográfica) (KANE; RYAN, 1998). O SIG integra a quantidade de árvores com grande 
capacidade de armazenamento e representação espacial de dados em vários níveis de detalhamento (LIMA NETO; BIONDI, 2012).

Cada vez mais as atividades de planejamento ambiental passaram a ser executadas em SIG, simulando a realidade do espaço geográfico, integrando informações espaciais e gerando mapas por meio do geoprocessamento. $O$ geoprocessamento é definido como o conjunto de tecnologias que integram as fases de coleta, processamento e uso de informações relacionadas ao espaço físico, seus cruzamentos, análises e produtos (SCHUCH, 2006), ou seja, o geoprocessamento pode ser utilizado para tomada de decisões.

O SIG é necessário também para obter informações sobre a distribuição espacial das árvores na cidade, consequentemente a composição das espécies, fitossanidade e demais condições (PAULEIT; DUHME, 2000). O inventário é o primeiro passo para a montagem de um banco de dados silvimétricos. Para Lima Neto e Biondi (2012, p. 642), "a realização de um inventário na arborização de ruas é o meio mais seguro de se conhecer o patrimônio arbóreo de uma cidade, fornecendo informações sobre prioridades de intervenções".

O inventário, junto com os elementos da geotecnologia, ajuda a tornar a gestão da arborização municipal mais completa e eficaz, além de que os usuários poderão ter acesso a outros dados digitais. A informatização dos dados, além de contribuir na manutenção e monitoramento da arborização, reduz custos para o gestor público.

Sendo assim, é salutar afirmar que engenheiros, geógrafos, arquitetos, urbanistas, botânicos, planejadores em geral, enfim, o conhecimento acadêmico e os gestores públicos devem combinar seus conhecimentos na gestão municipal da arborização das ruas e demais áreas verdes nas cidades.

$\mathrm{Na}$ cidade de Macapá, não foram identificados, até o momento, trabalhos realizados e publicados (na base de dados de periódicos CAPES e bibliotecas locais, por exemplo) nessa área com o nível de detalhamento adequado e necessário, que possam subsidiar ações futuras. Há mais de uma década a arborização não vem sendo planejada pelo poder público, sendo 
grande parte das árvores existentes decorrentes de campanhas pontuais ou de plantios voluntários sem a devida orientação e acompanhamento técnico (CASTRO, 2010).

Diante de tais inquietações, apresentou-se como objetivo geral elaborar um banco de dados SIG da arborização das vias urbanas de Macapá utilizando geotecnologias como subsídio para uma análise quali-quantitativa. Como objetivos secundários: identificar as espécies arbóreas existentes na cidade e também os problemas ocasionados pelo plantio inadequado.

\section{MATERIAL E MÉTODOS}

\section{1 Área de estudo}

O Município de Macapá possui uma área de $6.408,5$ km² e a população urbana na sede municipal perfaz um total de 369.519 habitantes (IBGE, 2010). Optou-se por trabalhar com a divisão de setores de acordo com o Plano Diretor de Desenvolvimento Urbano e Ambiental (PMM, 2004), no qual a cidade foi divida em três Unidades de Gestão Urbana: Macapá Centro, Macapá Norte e Macapá Sudoeste (Figura 1). 


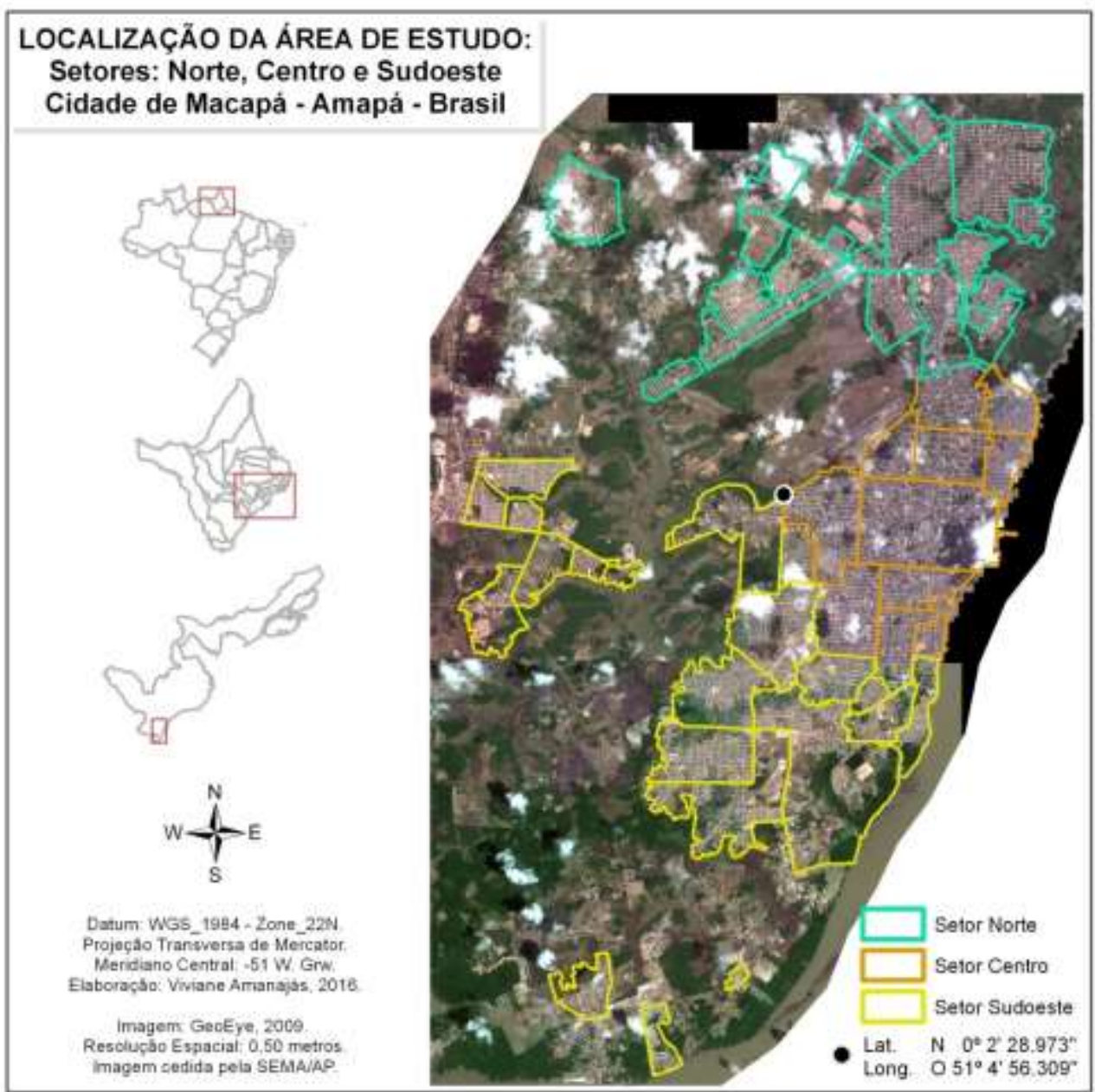

Figura 1: Imagem dos três setores da área urbana de Macapá, segundo o Plano Diretor.

As unidades de gestão foram utilizadas para direcionar o levantamento de campo utilizando os três grandes setores. Esta decisão permitiu organizar o levantamento de campo, como: cronograma, horários e a distribuição, através do sorteio das quadras, permitindo uma cobertura melhor da área do estudo. Também proporcionou um respaldo de cunho técnico, em razão de ter sido definido por um órgão oficial competente, neste caso a Prefeitura Municipal de Macapá - PMM, responsável pela definição de bairros e limites urbanos.

O setor Centro é o mais antigo da cidade, onde ocorreram as primeiras ocupações, com residências mais desenvolvidas, portanto, é onde se encontram os espécimes mais velhos. O setor Sudoeste é o único cuja área não é contínua, encontram-se bairros em áreas alagadas ou úmidas (regionalmente chamadas de áreas de ressaca) ocupadas irregularmente fruto 
da expansão desordenada nas últimas décadas. Já o setor Norte é a área onde atualmente o processo de expansão da cidade está mais intenso, ou seja, com bairros mais jovens.

\subsection{Coleta de dados}

Complementar à metodologia setorial, acrescentou-se dados da base cartográfica fornecida pela Coordenadoria de Geoprocessamento e Tecnologia da Informação da Secretaria de Estado do Meio Ambiente (GCTIA/SEMA). A base cartográfica da SEMA, elaborada em 2003 pela empresa TECNOMAPAS/MT é de uso público a toda sociedade civil organizada e é composta por temas para todo o Estado do Amapá. No caso do estudo da base urbana, composta por limite de quadras, arruamento, bairros, hidrografia, dentre outros, a escala é de 1:100.000. A base da SEMA foi utilizada para orientar o processo de espacialização e ajuste da arborização após o trabalho de campo, fornecendo o quantitativo total do número de quadras por bairro, além da quantidade de bairros contemplados por cada setor.

Como procedimento metodológico, para o levantamento arbóreo geral das quadras referentes aos três setores da área de estudo, optou-se por trabalhar com o método estatístico de amostragem aleatória sem reposição, devido ao elevado número de quadras e o curto período para o levantamento. O método estatístico determinou a quantidade de quadras (a amostra) através de sorteio.

Para a aplicação do método estatístico de amostragem, definiu-se que $10 \%$ da população total de cada setor é representativo para a realização do inventário. Posteriormente, utilizou-se o software BioEstat 4.0 (INSTITUTO MAMIRAUÁ, 2007), para aplicar o sorteio das quadras a serem pesquisadas em cada setor. É importante destacar que cada setor teve seu número de quadras numeradas, isto é as quadras foram numeradas de 0 a 2.445. A numeração foi importante na identificação de cada quadra durante a aplicação do método estatístico. A distribuição de quadras por bairro é apresentada na 
Tabela 1, assim como o percentual amostral (10\%) e seu respectivo número de quadras.

Tabela 1: Quadra sorteadas por setor.

\begin{tabular}{c|c|c}
\hline \multicolumn{1}{c|}{ Setor } & № total de quadras & $\begin{array}{c}\text { № de quadras } \\
\text { sorteadas }\end{array}$ \\
\hline Macapá Centro & 809 & 81 \\
\hline Macapá Norte & 798 & 80 \\
\hline Macapá Sudoeste & 838 & 84 \\
\hline Total & $\mathbf{2 . 4 4 5}$ & $\mathbf{2 4 5}$ \\
\hline
\end{tabular}

No total, o sorteio contemplou 41 bairros, loteamentos e conjuntos. Após a realização do sorteio, foram elaborados mapas e croquis da área urbana de Macapá, por setor e por bairro, destacando as quadras a serem inventariadas, como o exemplo da Figura 2.

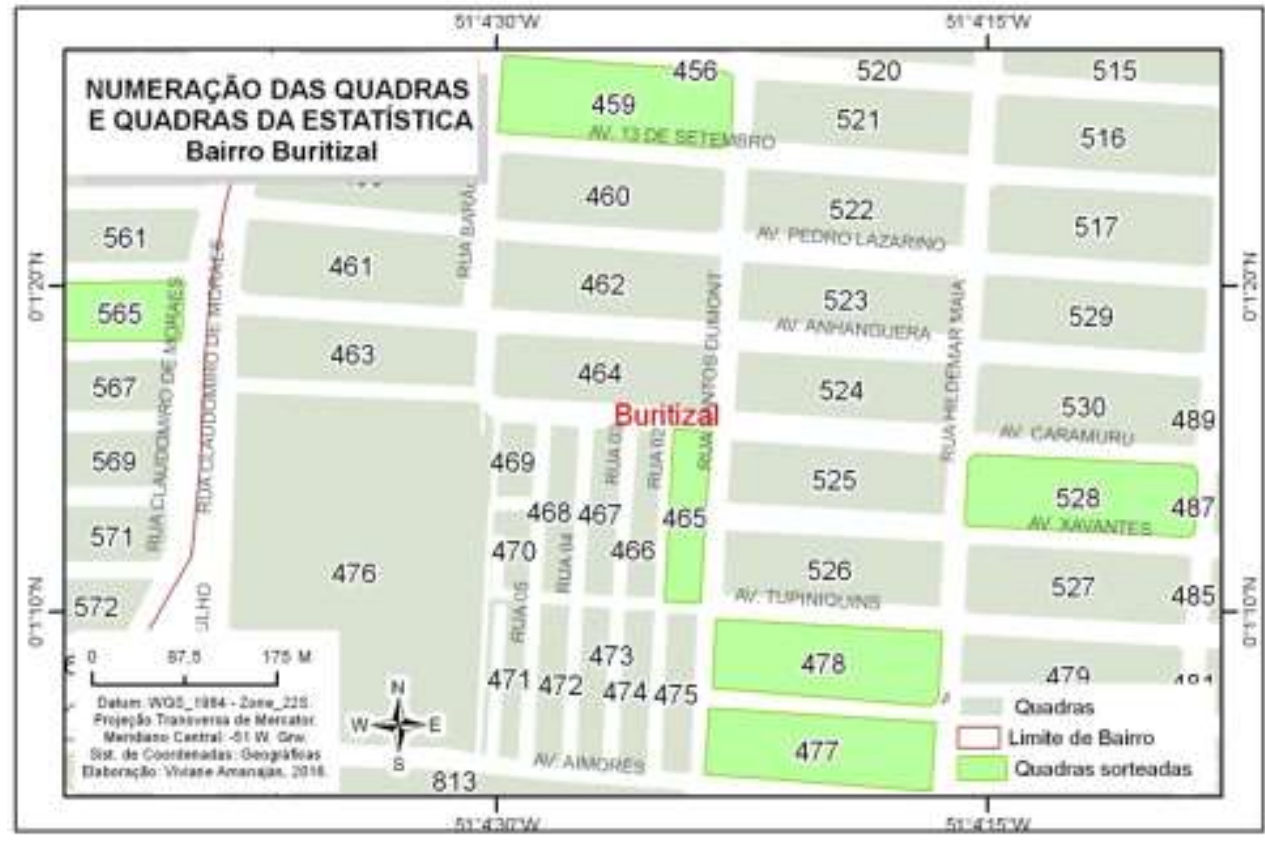

Figura 2: Mapa de localização das quadras sorteadas no Bairro Buritizal, setor Centro.

Para garantir a representatividade de $10 \%$ para os setores, foi calculado o intervalo de confiança com base nas amostras para toda população. O intervalo de confiança consiste no tamanho da amostra dividida pela população total, desta forma obtivemos a proporção da amostra. Esta proporção é 
considerada uma variável binominal, onde a proporção (p) e a amostra (n) devem ser > 5, ou seja, deve se aproximar de uma "normal". Neste caso foi calculado intervalo de confiança para a amostra de modo cumulativo. Então, somaram-se os quantitativos de cada setor (10\%), totalizando 245 quadras e dividiu-se pela população total de 2.445 quadras da área urbana de Macapá, o que resultou na proporção de 0,10. Para garantir a aproximação da normal, substituem-se os valores na fórmula n.p $>5$ e n.(1-p) >, assim, obtiveram-se os seguintes resultados $p=296,4>5$ e $n=220,05>5$, atendendo a regra de ser próximo a normal.

A partir daí, estabeleceu-se o nível de confiança e de representatividade de $95 \%$ para a amostra em estudo, utilizando-se para este cálculo o programa BioEstat 4.0 (INSTITUTO MAMIRAUÁ, 2007), que permitiu calcular o intervalo de confiança para a representatividade de $95 \%$ para as amostras. De acordo com o cálculo, o intervalo deve estar entre 8,8\% e 11,2\%, o que significa também que o cálculo do intervalo de confiança está correto, pois a soma das amostras de quadras sorteadas totaliza 245, que corresponde a $10,01 \%$, portanto dentro do intervalo.

Os dados foram coletados e preenchidos em formulário específico (Ficha de Campo), contendo as seguintes informações: Setor, Bairro; Quadra; Número de Ordem (árvore); Nome Vulgar; Fitossanidade; Situação da Raiz; Largura do Passeio Público; Afastamento Predial; Fiação (copa da árvore em relação à fiação elétrica); Circunferência do tronco; Copa (Longitudinal, Avanço Rua e Avanço Casa); Altura Total; Altura da 1aㅡ Bifurcação; e Necessidade de Poda. Foram cadastradas e georreferenciadas $100 \%$ das árvores existentes nas quadras sorteadas. Outros equipamentos e materiais utilizados para georreferenciar as árvores, extraindo as coordenadas da localização de cada árvore levantada no estudo: GPS (Global Position System) de navegação, com precisão variando de 2 a 3 metros; fita métrica, para medição da circunferência do tronco; máquina fotográfica digital, para ajudar na identificação de árvores desconhecidas. 
Para avaliar a necessidade de poda, a ficha de campo levou em consideração quatro níveis e seus respectivos códigos: 0 - Não (não necessita de poda); 1 - Leve (podas de limpeza, para retirada de galhos secos e doentes, ou para tutoramento); 2 - Pesada; e 3 - Drástica (estas duas últimas, dependeram do nível de interferência na rede elétrica, no trânsito e no passeio público, bem como entrelaçamento nas residências e pela fitossanidade comprometida).

Quanto à disposição das árvores em relação à fiação elétrica, foi utilizada uma figura anexa à ficha de campo onde são simuladas situações da posição da copa e os fios. Assim, utilizaram-se os códigos: 0 - Não tem (quando não há postes na parte da quadra onde estão as árvores); e os demais 1 - Abaixo, 2 - Meio, 3 - Acima.

Para a fitossanidade, as variáveis consideradas foram: 0 - Morta (apresenta danos irreversíveis de pragas, doenças ou graves danos físicos); 1 - Ruim (apresenta estado geral de declínio que podem ser severos danos de pragas, doenças ou defeitos físicos, mas que não aparenta morte iminente, e que requeira muito trabalho e tempo para a recuperação); 2 - Regular (apresenta condições de copa, tronco, raiz e vigor médios, cujos sinais de pragas doenças ou danos físicos são leves, necessitando de poda corretiva ou controle sanitário); e, finalmente, 3 - Boa (vigorosas e que não apresenta sinais de pragas, doenças ou injurias mecânicas, ou seja, boa coloração nas folhas, aspecto homogêneo ao longo dos galhos de todo vegetal, troncos sem quebra, lesões, necroses, com poucas podas de correção, raiz superficial sem ocasionar prejuízos para o calçamento).

Em relação ao sistema radicular, foram classificadas as condições: 0 Nenhum (raiz não se encontra exposta); 1 - Aponta (raiz está apontando na superfície do solo); 2 - Quebra (a raiz se expõe na superfície e apresenta sinais de quebra no passeio ou na rua); 3 - Destrói (ao emergir, a raiz ocasiona severas rupturas na superfície).

Trabalhos como de Salvi et al. (2011) caracterizam a fitossanidade do indivíduo de acordo com as condições da copa, raiz e tronco. 
A bifurcação foi classificada de acordo com a altura da primeira bifurcação do indivíduo em metros, dividida nos intervalos: menor que $1 \mathrm{~m}$; entre 1-1,5 m; entre 1,5-2 m; maior que $2 \mathrm{~m}$.

\subsection{Catálogo de árvores}

Com a utilização do ArcGIS 8.3 (ESRI, 2008) foi possível montar um arquivo de dados geoespacial, disponível pelos autores, para o poder público e comunidade científica em geral, para fins de consulta e futuras pesquisas complementares. Este arquivo é chamado de tabela de atributos (Figura 3), onde cada variável silvimétrica de todas as árvores foi cadastrada.

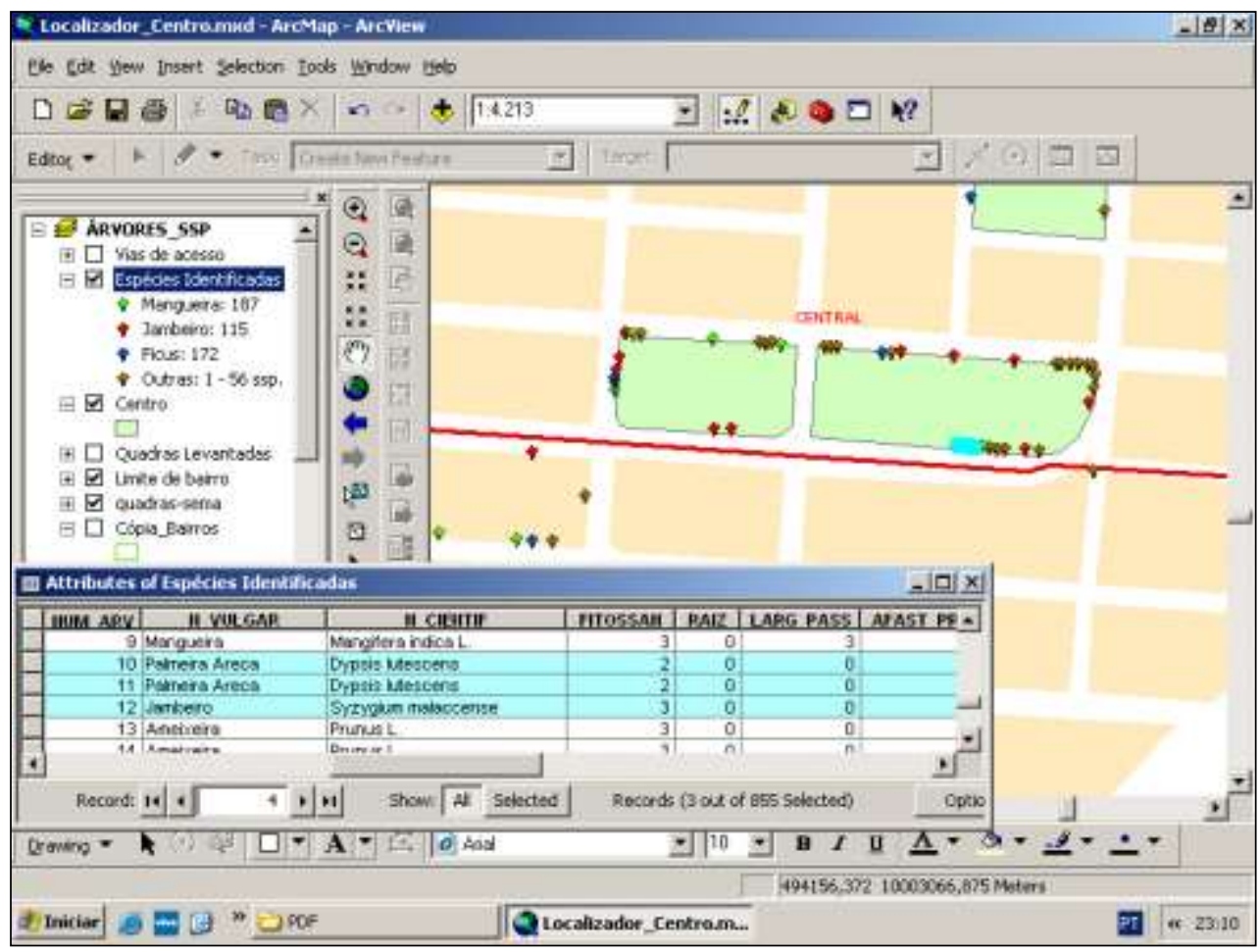

Figura 3: Visualização da tabela de atributos do ArcGIS, apresentando os shapefile das quadras com a espacialização das árvores no bairro central (superior direito). Na barra de conteúdos observamos os shapefile utilizados na legenda (superior esquerdo) e logo abaixo a tabela onde foram cadastradas a informações para cada árvore georreferenciada. Pode-se observar ainda que as três linhas selecionadas na tabela de atributos aparecem na tela do mapa dentro da quadra também destacadas em azul.

Concluído o levantamento dos dados de campo, procedeu-se com a digitalização das informações pertinentes. Nesta fase, utilizou-se o software ArcGIS 8.3 (ESRI, 2008) para o geoprocessamento das informações, 
associado ao programa de banco de dados Microsoft Excel 2003, onde cada árvore teve seu registro correspondente com sua posição geográfica, sua identificação botânica e suas variáveis silvimétricas registradas.

Foram confeccionados mapas temáticos para espacializar os resultados de campo (localização das árvores por quadra/bairro) de todas as quadras sorteadas, a exemplo da Figura 4, inclusive aquelas que eram desprovidas de arborização.

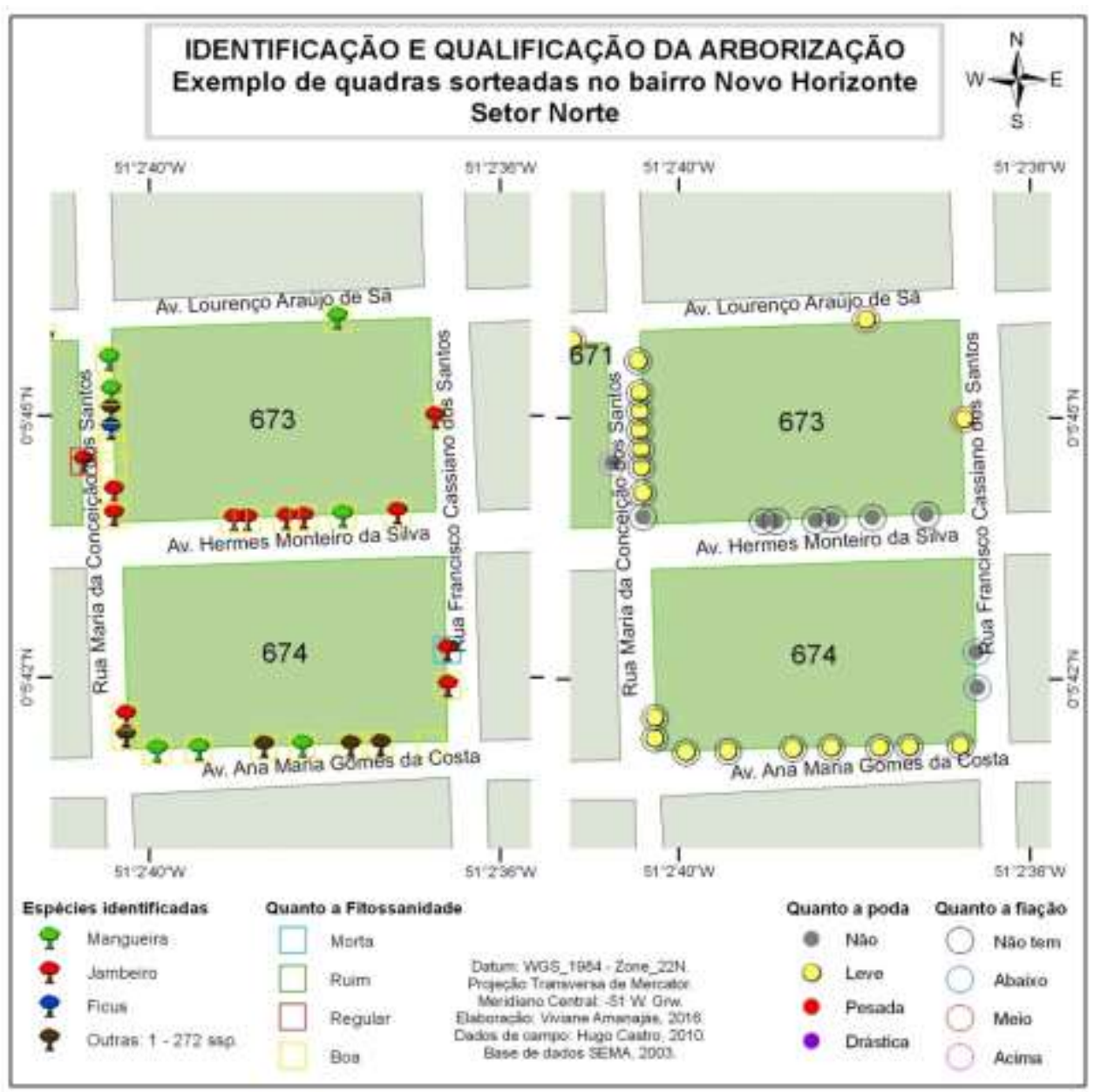

Figura 4: Mapa de identificação das espécies mais frequentes e qualificação da arborização quanto à fitossanidade, poda e fiação elétrica, em quadras sorteadas no Bairro Novo Horizonte, Setor Norte.

\section{RESULTADOS E DISCUSSÃO}

R. Ra'e Ga - Curitiba, v. 38, p. $146-168$, Dez/2016 
Embora a ficha de campo seja rica em informações, os dados analisados a seguir, de acordo com o objetivo deste texto, se aterão às análises de: escolha de espécies; situação de poda; disposição em relação à fiação elétrica; fitossanidade; situação da raiz; bifurcação.

\subsection{Da frequência de espécies}

Foram registradas todas as árvores das quadras sorteadas, totalizando 2.092 indivíduos, distribuídas em 57 espécies. Deste total, apenas 43 indivíduos não foram possíveis serem identificados, ou seja, 2,06\% do universo amostrado. A Tabela 2 apresenta as espécies mais ocorrentes, listadas em ordem de frequência.

Tabela 2: Lista das espécies identificadas mais frequentes.

\begin{tabular}{l|l|l|c|r}
\hline $\begin{array}{c}\text { N. } \\
\text { Ord }\end{array}$ & \multicolumn{1}{|c|}{$\begin{array}{c}\text { NOME } \\
\text { CIENTIFICO }\end{array}$} & \multicolumn{1}{|c|}{$\begin{array}{c}\text { NOME } \\
\text { VULGAR }\end{array}$} & $\begin{array}{c}\text { FREQUENCIA } \\
\text { ABSOULTA }\end{array}$ & $\begin{array}{r}\text { FREQUENCIA } \\
\text { RELATIVA (\%) }\end{array}$ \\
\hline 1 & Mangifera indica L. & Mangueira & 552 & 26,39 \\
\hline 2 & Ficus benjamina I. & Fícus & 392 & 18,74 \\
\hline 3 & Syzygium malaccense L. & Jambeiro & 257 & 12,28 \\
\hline 4 & Andira inermis (W. Wright) & Alvineira & 142 & 6,79 \\
\hline 5 & Roystonea oleraceae (Jacq.) & Palmeira Imperial & 119 & 5,69 \\
\hline 6 & Anacardium occidentale L. & Cajueiro & 80 & 3,82 \\
\hline 7 & Licania tomentosa (Benth.) & Oitizeiro & 76 & 3,63 \\
\hline 8 & Cocus nucifera I. & Coqueiro & 58 & 2,77 \\
\hline 9 & Terminalia catappa L. & Castanholeira & 39 & 1,86 \\
\hline 10 & Psidium guajava L. & Goiabeira & 35 & 1,67 \\
\hline 11 & Cycas sp & Palmeira Cica & 35 & 1,67 \\
\hline 12 & Euterpe oleraceaea Mart. & Açaizeiro & 34 & 1,63 \\
\hline 13 & $\begin{array}{l}\text { Clitoria fairchildiana } \text { R.A. } \\
\text { Howard }\end{array}$ & Palheteira & 31 & 1,48 \\
\hline 14 & Prunus L. & Ameixeira & 28 & 1,34 \\
\hline 15 & Carica papaya L. & Mamoeiro & 26 & 1,24 \\
\hline & \multicolumn{1}{|c|}{ TOTAL } & Outras & 188 & 9,01 \\
\hline & & $\mathbf{2 . 0 9 2}$ & $\mathbf{1 0 0 , 0 0}$ \\
\hline
\end{tabular}

Apesar de terem sido catalogadas 57 espécies, a cidade de Macapá sofre com sério problema de concentração de indivíduos da mesma espécie. 
Mangueiras (Mangifera indica), fícus (Ficus benjamina) e jambeiros (Syzygium malaccense), juntos, representam mais da metade $(57,41 \%)$ das árvores existentes nas vias urbanas, o que foge ao recomendado pela literatura. Para Grey e Deneke (1986), cada espécie não deve ultrapassar 15\% do total de indivíduos plantados, ou seja, "mangueiras" e "fícus" encontram-se fora dos padrões recomendados.

A maior diversidade de espécies de árvores na paisagem urbana se faz necessária, justamente para garantir o máximo de proteção contra infestações generalizadas de pragas e doenças (MELO et al., 2007; BARROS et al., 2010).

Ainda sobre o tema, o renomado Engenheiro Agrônomo Harri Lorenzi, no XIII Congresso Brasileiro de Aborização Urbana (2009), Rio Branco/AC, relatou verbalmente em palestra: "a arborização urbana deve ser heterogênea. Devemos copiar a natureza".

Houve também predominância de espécies frutíferas: $39 \%$ representados apenas por mangueiras e jambeiros. Apesar das espécies frutíferas serem atrativas para a avifauna, deve-se evitar o plantio dessas espécies em calçadas, pois esses frutos podem ocasionar prejuízos para veículos e pedestres que circulam no local. E em Macapá, além das espécies já plantadas serem predominantemente frutíferas, a população continua desejando este tipo, de acordo com o levantamento de percepção ambiental realizado na cidade (CASTRO; DIAS, 2013). Isto revela a necessidade de um trabalho de educação ambiental quanto a arboricultura para os munícipes.

Outro problema constatado é o percentual de espécies exóticas. Assim como em outras cidades do Brasil, na capital amapaense $56 \%$ das espécies registradas são exóticas e $44 \%$ são nativas do Brasil, além de que se forem levadas em consideração as espécies nativas regionais ou do bioma, certamente esse percentual diminuirá consideravelmente. O agravante é que, as três espécies mais ocorrentes mencionadas acima (mangueiras, fícus e jambeiros) não são naturais do Brasil, foram cultivadas e adaptadas, cuja origem é asiática. 
A utilização de espécies nativas em áreas urbanas deve ser incentivada com o intuito de proteger e valorizar a flora local (SILVA FILHO; BORTOLETO, 2005). A substituição contínua da flora nativa por plantas exóticas altera o ambiente natural que ainda existem nos centros urbanos, além de reduzir sua biodiversidade (AMARAL; GUILHERME, 2014).

Quanto ao número de espécimes registrados por setor, o destaque positivo é para o setor Centro, com $43 \%$ dos indivíduos registrados da área estudada (Tabela 3). Pode-se afirmar, portanto, que este setor é proporcionalmente o mais arborizado da cidade, ao contrário do setor Sudoeste, que é o menos arborizado, com frequência relativa de $24 \%$.

Tabela 3: Número de árvores registradas por setor.

\begin{tabular}{l|r|r}
\hline \multicolumn{1}{c|}{ Setor } & $\begin{array}{r}\text { № de árvores } \\
\text { georreferenciadas }\end{array}$ & $\begin{array}{c}\text { № de } \\
\text { espécies } \\
\text { identificadas }\end{array}$ \\
\hline Centro & $897(43 \%)$ & 38 \\
\hline Norte & $687(33 \%)$ & 31 \\
\hline Sudoeste & $508(24 \%)$ & 36 \\
\hline Total & $\mathbf{2 . 0 9 2 ( 1 0 0 \% )}$ & $\mathbf{5 7}$ \\
\hline
\end{tabular}

Com base na metodologia dos $10 \%$ da área de estudo, estima-se, portanto, que Macapá possui cerca de 21.000 árvores de rua. Significa dizer que para cada habitante da área urbana, há 0,07 árvores. Comparativamente, a cidade mais arborizada do país, Goiânia/GO, detém índice de 0,79 árvores plantadas em vias públicas por habitante (AMMA, 2008), ou seja, cerca de onze vezes maior que a capital amapaense.

\subsection{Quanto à poda}

As atividades anuais e sucessivas de podas ao longo do tempo danificam bastante a arborização de um modo geral. Há vários tipos de podas: de formação (para a muda) e as de limpeza (para retirada de ramos doentes, quebrados ou mal formados). Há também a poda que é feita para solucionar problemas decorrentes do plantio inadequado, neste caso, embora seja 
inconveniente, também é necessária. As podas devem ser feitas, tomando-se o cuidado de manter, o máximo possível, o formato original da árvore (EMER et al., 2013). Quando é realizada de maneira incorreta, pode afetar definitivamente sua estética.

Em média, a maior parte das árvores pesquisadas não necessita de poda. Entretanto, $40 \%$ carecem de algum serviço de manutenção, sendo 10\% com nível de poda pesada ou drástica (Tabela 4).

Tabela 4: Necessidade de poda.

\begin{tabular}{l|c|c|c|c}
\hline Nível de necessidade & Não & Leve & Pesada & Drástica \\
\hline $\begin{array}{l}\text { Média geral dos três } \\
\text { setores }\end{array}$ & $60 \%$ & $30 \%$ & $8 \%$ & $2 \%$ \\
\hline
\end{tabular}

O Centro, que concentra o maior número de indivíduos e os mais antigos, é o setor que mais carece de serviço de poda, com $49 \%$ das árvores registradas.

A falta de manutenção de árvores, com podas de galhos secos e doentes, bem como má realização de podas, como na Figura 5, associada à ação de ventos e chuvas fortes, facilita o tombamento do vegetal com risco de acidentes no trânsito e no passeio público.

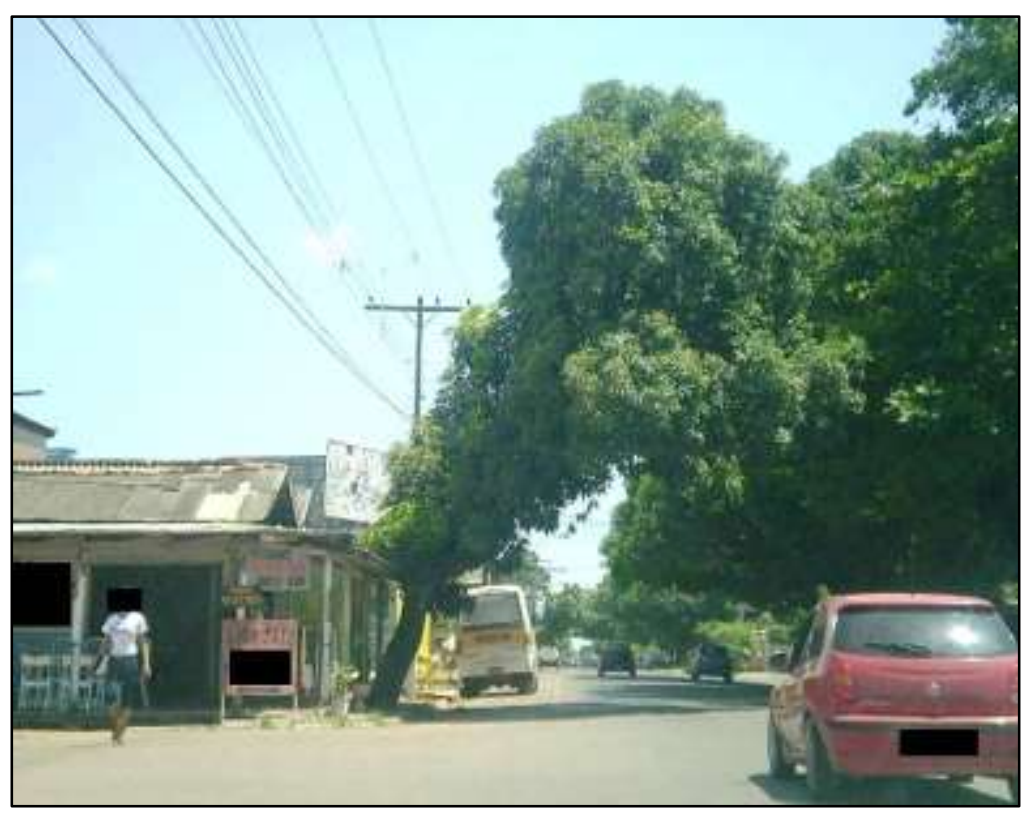

R. Ra'e Ga - Curitiba, v. 38, p. $146-168$, Dez/2016 
Figura 5: Poda má executada em uma mangueira (Mangifera indica L.) no setor Centro da cidade de Macapá, fevereiro de 2011.

\subsection{Quanto à fiação elétrica}

A rede elétrica na cidade de Macapá não atende a um padrão homogêneo. Encontram-se nas vias, postes com altura que variam de 6 a 12 metros. Essa variação prejudica o desenvolvimento das árvores já plantadas e a execução de futuros projetos.

Por isso, Soares (1998 apud Velasco et al., 2006), afirma que são grandes as dificuldades de se implantar o verde nas cidades, principalmente conciliado à presença de equipamentos urbanos, como instalações hidráulicas e redes elétricas, telefônicas ou sanitárias. Ainda assim, não se pode afirmar que a poda soluciona o problema da convivência entre árvore e fiação elétrica.

Vinte e cinco por cento das árvores estão abaixo da fiação e $28 \%$ apresentam a copa entre a rede de fios (Figura 6). Considerando que as espécies com maior abundância possuem porte médio e grande, como é o caso das mangueiras que podem chegar até 30 metros de altura, em poucos anos, os conflitos oriundos dessa incompatibilidade serão maiores dos que os atuais.

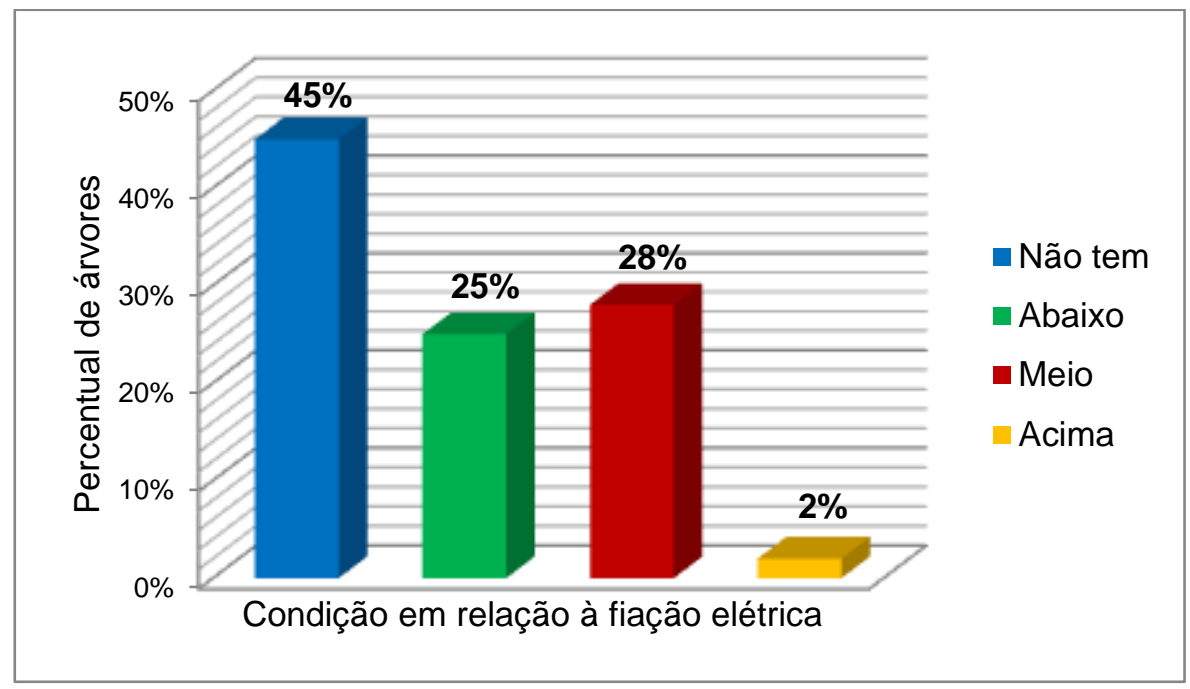

Figura 6: Gráfico Disposição das árvores quanto à fiação. 
O elevado índice de $45 \%$ classificado como "não tem", é devido à distribuição dos postes nas quadras. Se cada quadra possui quatro lados, dois lados possuem postes, isto é, estes $43 \%$ representam a parte da quadra que não apresenta postes. Se excluirmos esse dado e considerarmos os dados válidos (copa abaixo da fiação, no meio e acima) distribuídos proporcionalmente, o percentual fica: $45 \%, 51 \%$ e $4 \%$, respectivamente.

Trabalhos como de Leal et al. (2008), ressaltam que os custos de implantação da rede elétrica subterrânea é aproximadamente dez vezes maior que os custos da rede convencional, entretanto, por ter reduzido custo de manutenção e alta confiabilidade do sistema elétrico, seu uso demonstra ser viável e eficiente. Outra medida não tão adequada como a subterrânea, porém, melhor que a convencional, é investir em redes compactas de fiação aérea, as quais são menos onerosas que as convencionais e propiciam menos conflitos com árvores.

A coexistência harmônica da arborização urbana com o sistema elétrico só será possível, se houver um planejamento prévio tanto por parte do poder público estadual, através da concessionária de energia elétrica que irá implantar e explorar os seus serviços na cidade, como por parte do poder público municipal que irá implantar e manter a arborização de ruas, praças e jardins de suas cidades. Em Macapá, o Corpo de Bombeiros Militar também interfere e auxilia (quando necessário) em tal atividade realizando podas de emergência.

\subsection{Fitossanidade}

No geral, as árvores da cidade se encontram com boa situação fitossanitária (65\%). Trinta e cinco por cento tem algum tipo de prejuízo, com condição regular, ruim ou morta. E o alerta vai para o setor Centro, onde esse índice aumenta para 40\%. Em contraste, a região Norte da capital amapaense é o setor onde as árvores apresentam melhores condições fitossanitárias, com dois terços de sua abrangência e também os indivíduos mais jovens. 
É sabido também que parte da fitossanidade comprometida das árvores nas vias públicas são resultados da ação popular. O cidadão quando não deseja mais aquela árvore em frente a sua residência e quando o poder público não atende sua solicitação de remoção do vegetal, ele próprio provoca arranhuras no tronco da árvore até levar lentamente a morte.

\subsection{Situação da raiz das árvores}

Neste quesito, 27\% das árvores, em geral, apontam algum sinal de dano ao calçamento provocado pela raiz. A situação é mais acentuada no setor Centro onde esse índice representa 37\%, como demonstrado em um exemplo, na Figura 7.

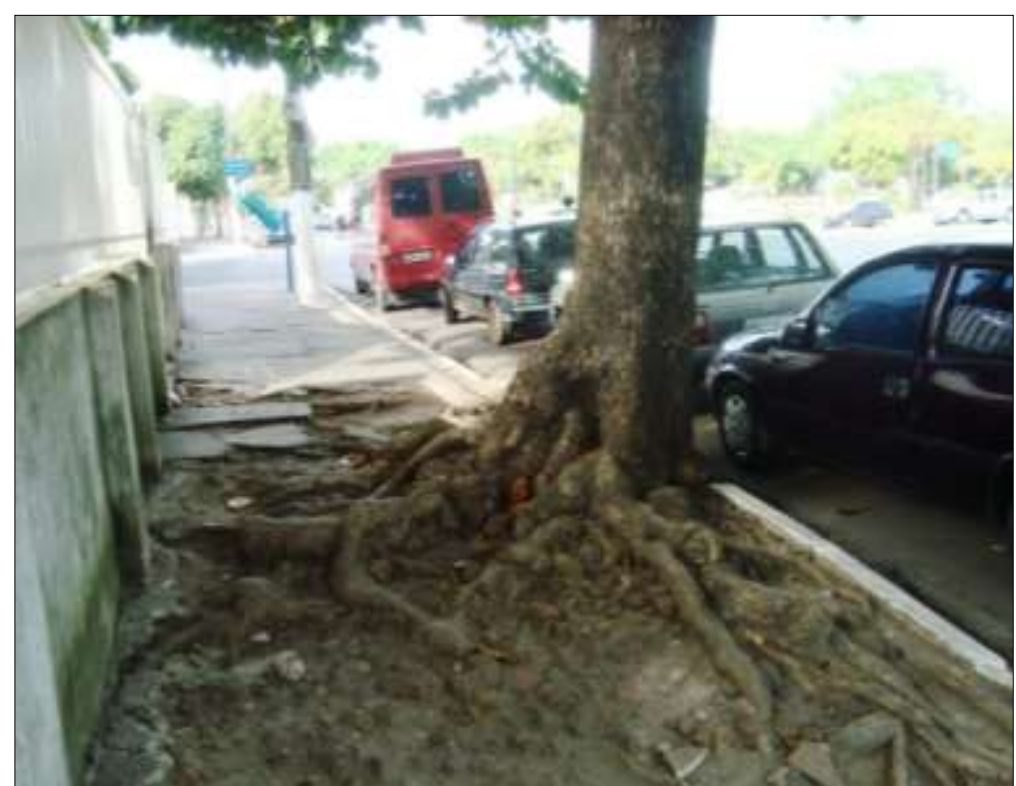

Figura 7: Calçada intransitável, completamente destruída pela raiz, no bairro central da cidade de Macapá, fevereiro 2011.

\subsection{Bifurcação}

Cinquenta e três por cento dos indivíduos registrados em toda cidade se apresentam com bifurcação abaixo de um metro, estando aquém dos padrões desejados. O destaque negativo é o setor Sudoeste, no qual $61 \%$ das árvores bifurcam precocemente. Árvores que bifurcam muito cedo são mais suscetíveis a problema de podas. Para evitar o problema da bifurcação baixa, deve-se dar 
trato adequado no momento do plantio da muda, com relação à profundidade da cava, tutoramento e poda dos ramos a medida que eles forem crescendo.

\section{CONSIDERAÇÕES FINAIS}

Através da disponibilização do banco de dados apresentado no artigo, espera-se que ele possa contribuir com a melhoria da qualidade de vida e paisagem urbana ambiental e assim, poder traçar propostas para um devido planejamento urbano.

Levantamentos semelhantes a este trabalho também podem ser desenvolvidos por uma plataforma de software livre, tornando os resultados do trabalho mais acessíveis, pois permitirá a divulgação, atualização e usos por diversos setores da sociedade civil, bem como por órgãos públicos.

O processo de avaliação da arborização, tanto qualitativo como quantitativo depende, assim, da realização de inventários, objetivo dessa pesquisa. O uso das geotecnologias serviu como suporte para obter uma resposta rápida sobre a problemática ambiental urbana. As pesquisas podem contribuir para o estímulo da discussão científica e intelectual do presente e do futuro da vegetação urbana de um modo geral.

\section{AGRADECIMENTOS}

Este artigo é parte do Trabalho de Conclusão de Curso em Geografia apresentado pelo autor à Universidade Federal do Amapá, cuja pesquisa foi apoiada pela Secretaria de Estado da Ciência e Tecnologia do Amapá SETEC (Bolsa de Iniciação Científica).

\section{REFERÊNCIAS}

AGÊNCIA MUNICIPAL DO MEIO AMBIENTE (AMMA). Plano Diretor de Arborização Urbana de Goiânia. Goiânia: AMMA, 2008.

AMARAL, E. V. E. de J.; GUILHERME, F. A. G. Arborização em praças no município de Jataí, GO, Brasil. REVSBAU, Piracicaba-SP, v.9, n.2, p 18-33, 2014. 
BARGOS, D. C.; MATIAS, L. F. Áreas verdes urbanas: um estudo de revisão e proposta conceitual. REVSBAU, Piracicaba-SP, v.6, n.3, p.172-188, 2011.

BARROS, E. F. S.; GUILHERME, F. A. G.; CARVALHO, R. dos S. Arborização urbana em quadras de diferentes padrões construtivos na cidade de Jataí. Revista Árvore, Viçosa-MG, v.34, n.2, p.287-295, 2010.

BIONDI, D. Arborização urbana aplicada à educação ambiental nas escolas. Curitiba: D. Biondi, 2008. 120p.

CASTRO, H. S. Geotecnologia, Percepção Ambiental e Planejamento: uma abordagem da arborização urbana de Macapá/AP. 2010. 92 f. Trabalho de Conclusão de Curso (Graduação em Geografia). Universidade Federal do Amapá, 2010.

CASTRO, H. S.; DIAS, T. C. A. de. C. Percepção Ambiental e Arborização Urbana em Macapá, Amapá. Biota Amazônia, Macapá-AP, v. 3, n. 3, p. 34-44, 2013.

EMER, A. A.; SILVA, L. da; CADORIN, D. A.; MELLO, N. A. Avaliação quantitativa e qualitativa da arborização do bairro Santa Terezinha na cidade de Pato Branco (PR). Ambiência, Guarapuava-PR, v. 9, n.1, p. 129-143, 2013.

ESRI. Environmental Systems Research Institute Inc. 2008. ArcGIS Desktop 8.3. New York. CD-ROM. Disponibilizado pela SEMA e UNIFAP, Macapá: [s.d].

GREY, G. W.; DENEKE, F. J. Urban Forestry. 2 ed. New York: John Wiley, 1986.

INSTITUTO BRASILEIRO DE GEOGRAFIA E ESTATíSTICA (IBGE). Censo Demográfico 2010.2 Disponível em: <http://www.ibge.gov.br/home/estatistica/populacao/censo2010/> Acesso em: 12 fev. 2015.

INSTITUTO MAMIRAUÁ. Software Bioestat, v. 4.0. Software Livre. Manaus: Instituto de Desenvolvimento Sustentável Mamirauá, Disponível em: <http://www.mamiraua.org.br/pt-br/downloads/programas/bioestat-versao-53/>. Acesso em: 10 abr. 2009. 
KANE, B.; RYAN, H. D. P. Locating trees using a Geographic Information System and the Global Positioning System. Journal of Arboriculture, [S. I.], v. 24, n.3, p. 135-143, 1998.

LEAL, L.; BIONDI, D.; ROCHADELLI, R. Custos de implantação e manutenção da arborização de ruas da cidade de Curitiba, PR. Revista Árvore, Viçosa-MG, v.32, n.3, p.557-565, 2008.

LIMA NETO, E. M.; BARDELLI-DA-SILVA, M. Y.; SILVA, A. R.; BIONDI, D. Arborização de ruas e acessibilidade no bairro centro de Curitiba-PR. REVSBAU, Piracicaba-SP, v.5, n.4, p.40-56, 2010.

LIMA NETO, E. M.; BIONDI, D. Detecção de árvores de ruas da cidade de Curitiba, PR, utilizando fotografias aéreas. Revista Brasileira de Ciências Agrárias, Recife, v.7, n.4, p.641-647, 2012.

LONDE, P. R.; MENDES, P. C. A influência das áreas verdes na qualidade de vida urbana. Hygeia, [Uberlândia], v. 10, n. 18, p. 264-272, 2014.

MELO, R. R.; LIRA FILHO, J. A.; JÚNIOR, R. F. Diagnóstico qualitativo e quantitativo da arborização urbana no bairro Bivar Olinto, Patos, Paraíba. REVSBAU, Piracicaba-SP, v.2, n.1, p.64-80, 2007.

MILANO, M. S. Curso sobre arborização urbana. Curitiba: FUPEF, 1991.

PAULEIT, S.; DUHME, F. GIS assessment of Munich's urban forest structure for urban planning. Journal of Arboriculture, [S. I.], v. 26, n. 3, p. 133-141, 2000.

PREFEITURA MUNICIPAL DE MACAPÁ (PMM). Plano Diretor de Desenvolvimento Urbano e Ambiental de Macapá. Lei Complementar 026/2004-PMM de 20 jan. 2004. Macapá: SEMPLA, 2004. Disponível em: <http://www.macapa.ap.gov.br/arquivos/planodiretormacap/PLANO\%20DIRET OR\%20DE\%20MACAPA.pdf> Acesso em: 19 dez. 2014.

SANCHOTENE, M. do C. C. Desenvolvimento e Perspectivas da Arborização Urbana no Brasil. In: CONGRESSO BRASILEIRO DE ARBORIZAÇÃO URBANA, 2, 1994, São Luis, MA; ENCONTRO NACIONAL SOBRE ARBORIZAÇÃO URBANA, V, 1994, São Luis, MA, Anais... São Luis: UEMA, 1994. 
SCHUCH, M. I. S. Arborização urbana: uma contribuição à qualidade de vida com uso de geotecnologias. 2006. 102 f. Dissertação (Mestrado em Geomática). Centro de Ciências Rurais - UFSM, Santa Maria-RS, 2006.

SALVI, L. T.; HARDT, L. P. A.; ROVEDDER, C. E.; FONTANA, C. S. Arborização ao longo de ruas - túneis verdes - em Porto Alegre, RS, Brasil: avaliação quantitativa e qualitativa. Revista Árvore, Viçosa, v. 35, n. 2, p. 233243, 2011.

SILVA FILHO, D. F.; BORTOLETO, S. Uso de indicadores de diversidade na definição de plano de manejo da arborização viária de águas de São Pedro-SP. Revista Árvore, Viçosa, v. 29, n. 6, p. 973-982, 2005.

SZEREMETA, B.; ZANNIN, P. H. T. A importância dos parques urbanos e áreas verdes na promoção da qualidade de vida em cidades. Ra'e Ga - O Espaço Geográfico em Análise, Curitiba, v. 29, p. 177-193, 2013.

VELASCO, G. D. N.; LIMA, A. M. L. P.; COUTO, H. T. Z. Análise comparativa dos custos de diferentes redes de distribuição de energia elétrica no contexto da arborização urbana. Revista Árvore. Viçosa-MG, vol. 30, n. 4, p. 679-686, 2006. 